\title{
Açık kanalda batmış bitkinin akıma etkisi
}

\author{
Didem YILMAZER ${ }^{1,}$, Ayşe YÜKSEL OZAN ${ }^{2}$

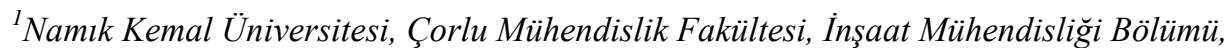 \\ Çorlu-TEKIRDA $\breve{G}$ \\ ${ }^{2}$ Adnan Menderes Üniversitesi, Mühendislik Fakültesi, İnşaat Mühendisliği Bölümü, AYDIN \\ Geliş Tarihi (Recived Date): 10.05.2017 \\ Kabul Tarihi (Accepted Date): 23.07.2017
}

\section{Özet}

Son 30 yılda ekosistem ve dünya için vazgeçilmez bir rolü olan bitki tarlalarının kıyı ve akarsu hidroliği üzerindeki etkilerini incelemek çok önem kazanmıştır. Akım ve bitki örtüsü arasındaki girişim, katı madde taşınımını, akarsu jeomorfolojisini ve akarsu bölgesindeki yaşam alanını önemli derecede etkilemektedir. Doğal bitki tarlalarının şüphesiz en önemli özelliği rastgele bir karaktere sahip olmalarldır. Doğal bir bitki alanında, bitkinin yüksekliği, çapı, şekli, bükülme sertliği ve mekânsal dăğlım gibi birçok parametre rastgele olarak olaya etkili olmaktadır [2]. Bu nedenlerden dolayl, akım alanı ve bitki örtüsü arasında meydana gelen etkileşimin anlaşılması akarsu düzenlemeleri ve akım kontrol durumları için oldukça önemlidir. Bu çalışmada, kısmi bitki örtüsüne sahip akarsularda bulunan batık bitki örtüsü ve akım arasındaki etkileşim deneysel olarak incelenmiştir. Deneylerde, düşük ve yüksek yoğunlukta $\left(\mathrm{N} 1=172 \mathrm{IP} / \mathrm{m}^{2}\right.$ ve $N 2=1142 \mathrm{IP} / \mathrm{m}^{2}$ ) olmak üzere iki farkl bitki yoğunluğu kullanılmıştır. Kanalda $x$ ekseni yönünde (13 farkl noktada), yanal mesafelerde (11 farkl noktada) ADV (Acoustic Doppler Velocimeter) ile üç farklı derinlikte düşey hız ölçümleri yapılmıştır. Bu çalışmada bitki tabakasının varlığının, akımın hızında bir azalmaya neden olduğu ve bitki yoğunluğunun artışıla beraber hızdaki azalmanın daha etkin bir hale geldiği görülmüştür. Bu çalışmanın, literatürde art-iz bölgesi ile ilgili sinırlı sayıda olan çalışmalara katkı sağlayacă̆ı düşünülmektedir.

Anahtar kelimeler: Bitki parçası, art-iz bölgesi, batık bitki

\footnotetext{
*Didem YILMAZER, dyilmazer@nku.edu.tr, http://orcid.org/0000-0001-6947-8262 Ayşe YÜKSEL OZAN, ayseyukselozan@gmail.com, http://orcid.org/0000-0003-1931-3528
} 


\title{
The effect of submerged vegetation on the open channel flow
}

\begin{abstract}
In the last 30 years, it has become very important to examine the effects of vegetation fields on the coastal and fluvial areas, which have an indispensable role for the ecosystem and the world. The interference between current and vegetation greatly affects the sediment transport, river geomorphology and habitat in the river area. Doubtlessly, one of the most important features of natural vegetation fields is the randomness. In a natural vegetation field, many parameters such as the diameter and height of the plants, their shape, bending stiffness and spatial distribution can be observed as random parameters [2]. For these reasons the interaction between flow and vegetation should be understand very well in terms of river management and flow control. In this study, interaction between submerged vegetation layer and flow at partially vegetated river flows was investigated experimentally. Rare and dense vegetation intensity $\left(N 1=172 \mathrm{IP} / \mathrm{m}^{2}\right.$ and $\left.\mathrm{N} 2=1142 \mathrm{IP} / \mathrm{m}^{2}\right)$ was considered in the experiments. Velocity measurements were made at three different depths in the channel $x$-axis direction (at 13 points) and y-axis direction (at 11 points) using ADV (Acoustic Doppler Velocimeter). In this study, it was observed that the presence of the plant caused a decrease in the current speed and with the increase of the plant density, the reduction in speed became more pronounced. It is assumed that this study will contribute to the understanding of wake region.
\end{abstract}

Keywords: Vegetation patch, wake region, submerged vegetation

\section{Giriş}

Bitki tarlalarının sulak çevrenin sürdürülebilir gelişiminde çok önemli bir rolü vardır. Bitki tarlaları ayrıca akımın hidrodinamik yapısını da belirgin olarak etkilemektedir. Hidrodinamik koşulların değişmesi ile batık bitki örtüsü, su ekosistemindeki sediment taşınımını, besin sağlanmasını, kirleticileri, çözünmüş oksijen ve faunayı ciddi olarak etkileyebilir [4,12] Bitkili alanların kıyı ve akarsu hidrodinamiği üzerine olan etkileri üzerine yapılan araştırmalar son otuz yılda önem kazanmıştır. Akarsular, haliçler, deltalar ve pek çok kıyı alanlarında varlık gösteren deniz bitkilerinin ekosistemin dengesinde önemli roller üstlendikleri bilinmektedir. Akım alanı ve bitki örtüsü arasında meydana gelen etkileşimin anlaşılması akarsu düzenlemeleri ve akım kontrol durumları için oldukça önemlidir. Açık kanal akımlarında bulunan bitki örtüsü akıma karşı bir direnç göstermekte, su seviyesinin yükselmesine ve debi kapasitesinin azalmasına neden olmaktadır. Bu direnç mekanizması taşkın güvenliği açısından çok önemlidir ve dikkatle incelenmesi gerekmektedir.

Doğada, akarsularda bulunan bitki tabakaları iki farklı şekilde sınıflandırılmaktadır.

1) Bitki tabakasının yoğunluğuna göre. Bunlar, düşük, orta (geçiş) ve yüksek yoğunlukta bitki dağılımı olarak verilmektedir. Batık bitki tabakası için farklı bitki yoğunluklarının sınıflandırması Şekil 1'de görülmektedir.

2) Bitki tabakasının su derinliğine göre rölatif yüksekliğine göre $(H / h)$. Buna ait bir görüntü Şekil 2'de verilmektedir. 

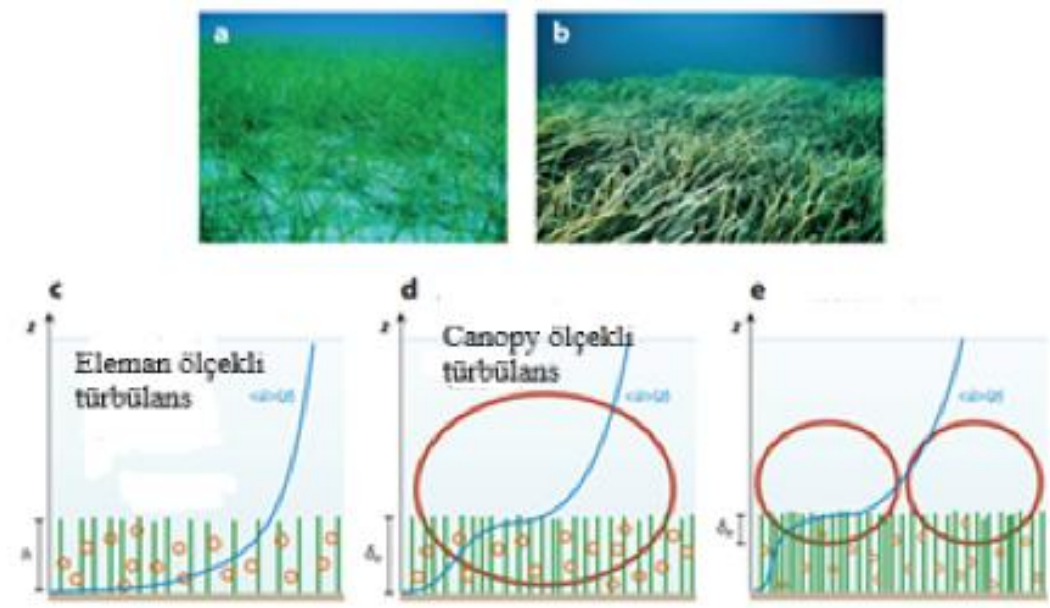

Duşuk yoğunlukta (seyrek) bitki tabakası (ah<<0.1)
Orta yoğunlukta bitki tabakası (ah:0.1)
Yuksek yogunlukta bitki tabakası (ah>>0.1)

Şekil 1. Farklı yoğunluktaki batık bitki tabakaları, a) Düşük yoğunlukta (seyrek) deniz yosunu (Cymodocea nodosa), b) Yüksek yoğunlukta deniz yosunu (Posidonia oceanica), c) Düşük yoğunlukta (seyrek) bitki tabakası (ah<<0.1), d) Orta yoğunlukta

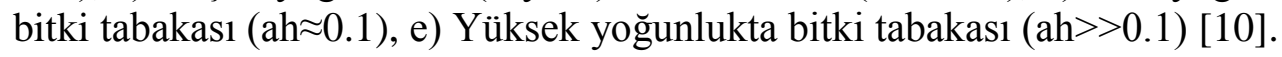

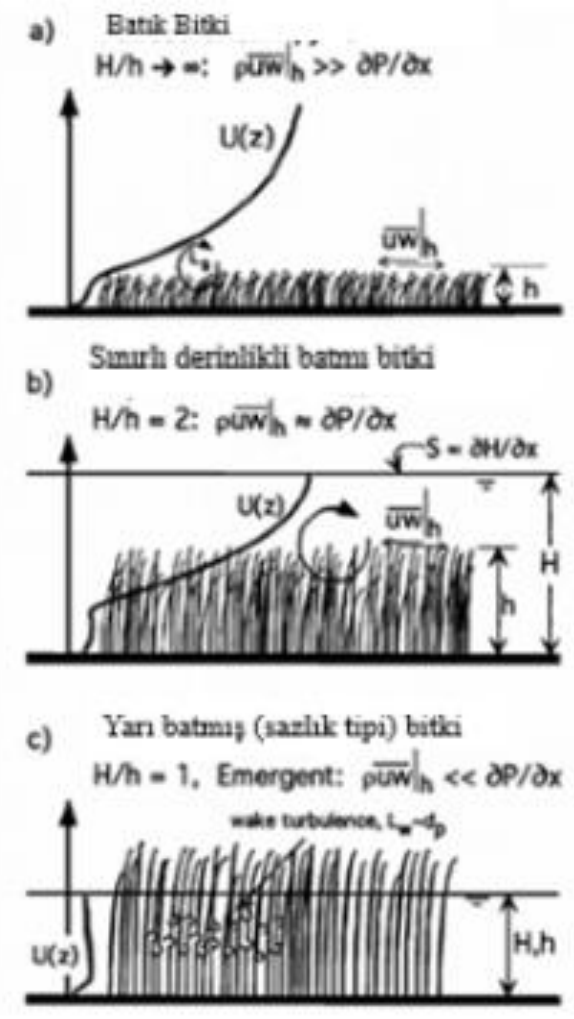

Şekil 2. Akarsularda oluşan farklı rölatif bitki derinliklerinin (H/h) sınıflandırılması [11] a)Batık bitki b)Sınırlı derinlikteki bitki c)Yarı batmış (sazlık tipi) bitki

Bitki-akım etkileşimi pek çok araştırmacı tarafından farklı kabuller altında incelenmiş olup akım-bitki etkileşiminde enerji sönümlenmesini konu alan pek çok çalışma bulunmaktadır. Stephen ve Gutknecht (2002)'de akarsu akımları için, eşdeğer kum pürüzlülügü yardımıyla bitkilerin akım direncini tanımlamak istemiş ve çakıl taşları 
üzerinde küçük rölatif batıklık akışında, batıklığın azalmasıyla birlikte türbülans yoğunluklarında görülen azalmanın, esnek bitki üzerinde gözlenmediğini belirtmişlerdir [18]. Järvelä (2005)'de akım yapısını incelemek için canlı bitkiler ile kanal deneyleri yapmış ve batmış haldeki canlı bitki üzerindeki akım yapısının esnek yapay bitkiler üzerindeki akım yapısı ile muadil olduğunu gözlemlemiştir [8]. Akgül vd. (2013)'de dalga baseninde yapay bitkiler kullanarak 3 farklı düzenli dalga serisi ile test yapmıştır. Yapılan deneyler neticesinde bitkilerin gelen dalga için bir engel oluşturduğu ve dalga yüksekliğinde bir azalma olduğunu gözlemlemiştir [2]. Huai vd. (2009)'da açık kanal akımları için batmış bitki etkisinin hız dağılımına etkilerini incelemişlerdir [6]. Zhu ve Chen (2015), su dalgası ve batmış esnek bitkiler arasındaki etkileşimi simüle etmek için tam birleşik dalga-bitki modeli geliştirmiş, analiz etmiş ve değerlendirmişlerdir [22]. Järvelä (2003), çalılık kaplı taşkın yataklarındaki düşük hızlı ve tufan koşullarındaki akım direnci üzerine çalışmıştır [7]. Afzalimehr vd. (2010)'da doğrusal, boyuna eğimli bir kanalda, bitki örtüsünün akım üzerindeki etkilerini deneysel olarak araştırmışlardır. Çakıl bir taban üzerine yerleştirilen bitki örtüsünde ADV hız ölçümleri yapmışlar ve akım alanına ait hız ve kayma gerilmesi dağılımlarını belirlemişlerdir [1]. Yüksel Ozan (2016)'da sınırlı uzunlukta batık bitki parçasının etkisindeki akım yapısını deneysel olarak araştırmış ve hız dağılımının kanal en kesiti boyunca logaritmik hız dağılımına uygun olduğunu ve bitki tabakasının, sınırlı uzunluğuna ve genişliğine rağmen akım hızında ciddi bir azalmaya neden olduğunu gözlemlemiştir [21]. Neph ve Vivoni (2000), Nezu ve Okamoto (2010)'da yaptıkları çalışmalarda, nehirlerde ve nehir kıyılarında meydana gelen bitkilenmenin akım alanını hidrodinamik olarak belirgin şekilde etkilediğini ve aynı zamanda akımı engelleyerek ortalama hız, Reynolds gerilimi ve türbülans şiddeti gibi akım karakteristiklerini değiştirerek katı madde taşınımına tesir ettiğini belirtmişlerdir [11, 13]. Haung vd. (1999), geniş ve dar taşkın yatağına sahip açık birleşik kanalların bitkilenmiş taşkın yataklarında oluşan akımın hidrodinamik yapısı ve taşkın salınım kapasitesi hakkında çalışmışlardır [5]. Ni ve Gu (2005), Manning katsayısı hakkında deneysel çalışmalar yapmışlardır. Deneylerde sazlık için PVC malzemesinden yapılmış kamış kullanmışlardır. Deneylerde, batık olmayan kamış ve kararlı uniform olmayan akım koşullarını dikkate almışlardır [14]. Okamoto ve Nezu (2013) çalışmalarında su bitki örtüsünün doğal nehirlerde sonlu uzunluklu parçalar halinde ve farklı batıklık oranlarında oluştuğundan ve bu alanlarda bitki örtü parçası kenarında kesme tabakası oluşmayıp, bitkilenmenin boyuna yayılım kütle ve momentum taşınımına önemli ölçüde katkıda bulunduğundan bahsetmişlerdir [15]. Raupach (1988), bitki tarlasının içindeki ve üstündeki türbülansın tutarlı ve organize olduğunu gözlemlemiş ve bu organize hareketin karakterine açıklık getirmeye çalışmıştır. Bu çalışmada, akarsu tabanı kısmi olarak batık bitki ile kaplandığında akım yapısı üzerindeki meydana gelen değişiklikler deneysel olarak araştırılmıştır Bunun için, laboratuvar ortamında oluşturulan yapay bitki ortamında, sabit debi ve su derinliğinde iki farklı bitki yoğunluğunda, ADV hızölçer ile farklı kesitlerde hız ölçümleri gerçekleştirilmiştir [16]. Fischer-Antze, T. vd. (2001) yaptıkları çalışmada, kısmi bitkilendirmenin yapıldığı açık kanalda, hız dağılımını 3 boyutlu model kullanarak hesaplamışlar, Navier Stokes denklemlerini türbülans modelini ve SIMPLE metodunu kullanarak çözmüşlerdir. Bitki düşey silindir kullanılarak modellenmiştir. Yüksek pürüzlülük değerleri yerine bu metodun kullanılması ile bitkinin sadece taban yakınındaki değil tüm derinliklerdeki etkisinin görülmesi sağlanmıştır. Model, kısmi olarak bitkilendirilmiş doğrusal kanalda uniform akımla yapılan üç farklı deney ile test edilmiştir. Çalışmada hız ve bitki yoğunluğu düşeyde ve yatayda değiştirilmiş ve değişik en kesit şekilleri kullanılmıştır. Çalışmada ölçülen ve hesaplanan hız profillerinin oldukça uyumlu olduğu gözlenmiştir [3]. Li, Y. vd. (2014), açık kanalda, 
batmış bitkinin, akım yapısı üzerindeki, etkisini 3D ADV kullanarak deneysel olarak araştırmışlar ve yapay bitkinin kullanıldığ 1 bu çalışmada, akım yapısının batmış bitkinin varlığından fark edilebilir şekilde etkilendiğini gözlemlemişlerdir. Çalışma, bitki tarlasının mansap tarafında akımın tekrar dengeli hale geldiği mesafenin belirlenmesi açısından da önem arz etmektedir[9]. Wilson, C.A.M.E. (2007), batmış esnek bitkilerin hidrolik pürüzlülük parametrelerinin, derinlikle değişimini incelemiştir. Çalışmasında, bitki sap yüksekliğinin, bitki tipinin ve batıklık derecesinin akım direncine etkisini kanopi kullanarak araştırmıştır. Deneysel çalışma sonucunda, derinlik azaldıkça Manning pürüzlülük katsayısının arttığını ve daha düşük bitki batıklığında asimptotik bir sabite ulaştı̆̆ını gözlemlemiştir. Sabitin, bitki yüksekliğine ve bitki özelliklerine bağlı olduğu sonucuna varmıştır [20]. Bu çalışmada, $d=1.0 \mathrm{~cm}$ çapında, $\mathrm{h}_{\mathrm{v}}=5.0 \mathrm{~cm}$ yüksekliğinde silindirik cisimler bitki yerine kullanılmış ve $\mathrm{N}_{1}=1142 \mathrm{IP} / \mathrm{m}^{2}$ (yüksek yoğunluklu) ve $\mathrm{N}_{2}=172 \mathrm{IP} / \mathrm{m}^{2}$ (düşük yoğunluklu) olarak iki farklı durum için deney yapılmış, deney verileri bitkisiz durumda kanalda yapılan hız ölçümleri ile karşılaştırılmıştır. Çalışmada bitki yoğunluğunun akım yapısına etkisinin incelenmesi amaçlanmıştır. Değişik bitki yükseklik ve yoğunlukları ile yapılan deney verilerini karşılaştırmaları açısından araştırmacılara yarar sağlaması amaçlanmıştır.

\section{Deneysel çalışmalar}

\subsection{Deney kanalı}

Deneyler, Adnan Menderes Üniversitesi, Mühendislik Fakültesi, İnşaat Mühendisliği Laboratuvarına kurulan $11.00 \mathrm{~m}$ uzunluğunda, $1.20 \mathrm{~m}$ genişliğinde ve $0.75 \mathrm{~m}$ yüksekliğinde, her iki tarafı cam, dikdörtgen kesitli doğrusal bir kanalda gerçekleştirilmiştir. Şekil 3'de kanala ait fotoğraflar, Şekil 4'de inşaa edilen kanalın kesitleri görülmektedir. Kanalda akım, su devir daimi yapılarak sağlanmıştır. Bunun için kanalın yanına bir pompa yerleştirilmiştir. Bu pompa ile kanaldan alınan su, devir daim borusu aracılığı ile kanala geri basılarak akım oluşturulmuştur. Hız ölçümlerinde kullanılan ADV, bir limnimetreye monte edilerek düşeyde kontrollü bir şekilde hareket etmesi sağlanmıştır. Oluşturulan bu sistem, kanal üzerinde enine ve boyuna hareket edebilen tekerlekli bir arabaya takılarak, ADV'nin üç boyutta hareket etmesi sağlanmıştır. Böylece, istenilen noktada ölçüm yapılabilmiştir. Kanalda suyun boşaltılması, kanalın memba ucuna bağlanan bir pompa ile suyun şebeke sistemine aktarılması ile sağlanmıştır. Kanalın tabanı, öncelikli olarak beton ile kaplanarak sızdırmazlık sağlanmış ardından oluşturulması planlanan bitki örtüsünü yerleştirebilmek için kontrplak tabaka ile kaplanmıştır. Kanalın memba ve mansabında çalkantının önlenmesi amacıyla delikli tuğla ile sönümleme alanı yaratılmıştır.

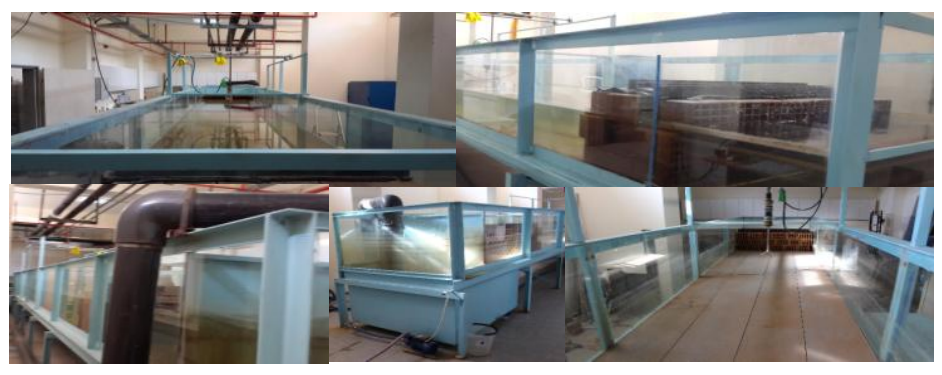

Şekil 3. Doğrusal kanalın farklı görünüşleri 

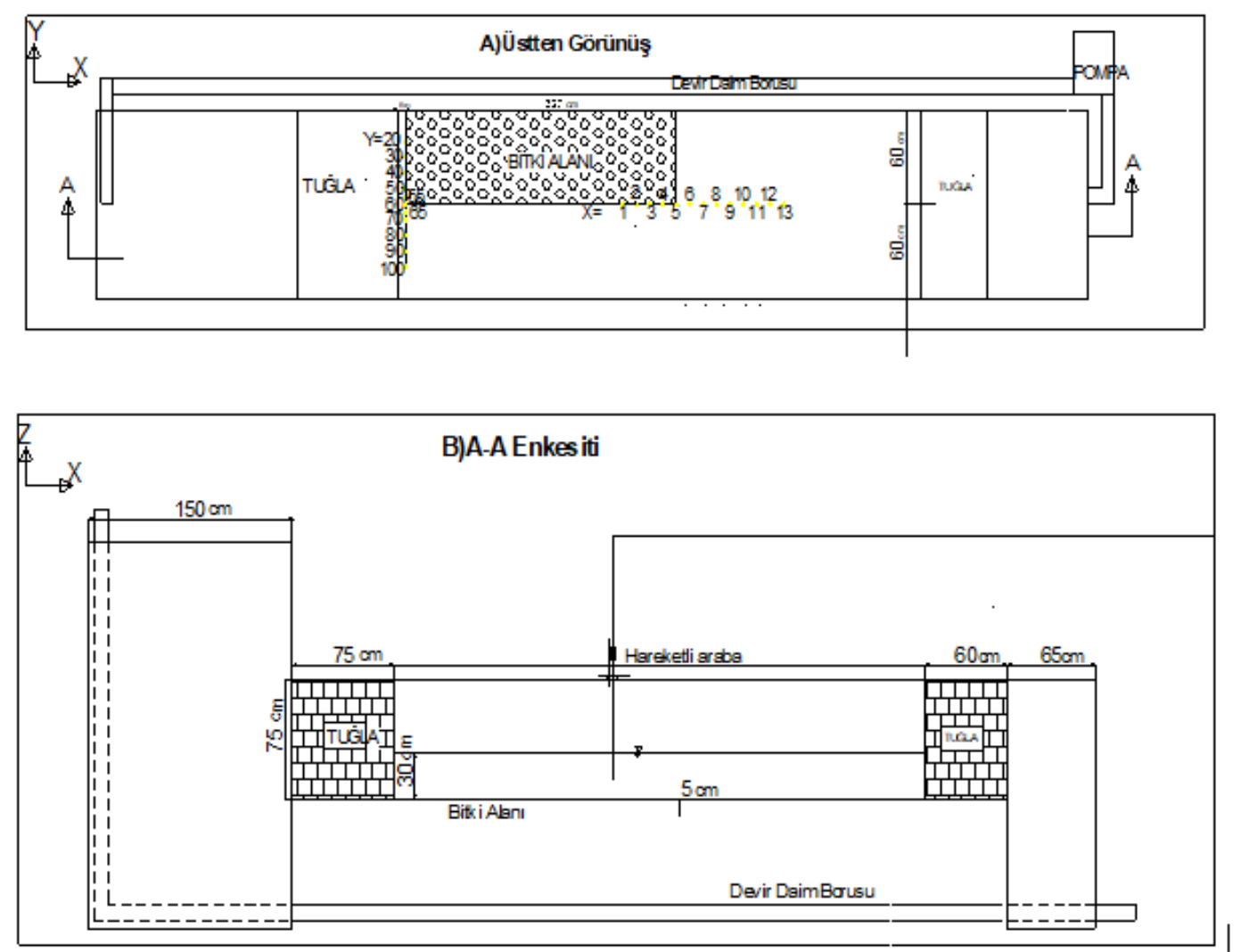

Şekil 4. Doğrusal açık kanal, a) Üstten görünüş, b) A-A En kesit görünüşü

\section{$2.2 \mathrm{Hız}$ ölçümü}

Deneylerde SONTEK-Akustik Dopler Hiz Ölçer (Acoustic Doppler Velocimeter- ADV) kullanılmıştır. ADV, akustik dopler prensibine dayanan yüksek doğruluğa sahip, üç doğrultudaki hız bileşenlerini ölçen bir hızölçerdir. Özellikle sınır tabakası ve bazı türbülans ölçümleri için oldukça elverişlidir ve birçok disiplinde kullanılmaktadır [17]. ADV hızölçer ile alınan veriler WinADV32(v.2.27) programı kullanılarak işlenmiştir[19].

\subsection{Bitki örtüsü}

Çalışmada dikkate alınan bitki örtüsü $320 \mathrm{~cm}$ uzunluğunda ve $60 \mathrm{~cm}$ genişliğinde, kanal en kesitinin yarısını kaplayacak şekilde seçilmiştir. Bitki örtüsü, $\mathrm{d}=1.0 \mathrm{~cm}$ çapında, $\mathrm{h}_{\mathrm{v}}=5.0 \mathrm{~cm}$ yüksekliğinde rijit plastik silindirlerden, yüksek yoğunlukta $\left(\mathrm{N}_{1}=1142 \mathrm{IP} / \mathrm{m}^{2}\right)$ ve düşük yoğunlukta $\left(\mathrm{N}_{2}=172 \mathrm{IP} / \mathrm{m}^{2}\right)$ oluşturulmuştur. Burada, IP $/ \mathrm{m}^{2}$ birim alandaki bitki sayısını ifade etmektedir. Deneyler süresince su seviyesinin $\mathrm{H}=30 \mathrm{~cm}$ olması sağlanmıştır ve ortalama akım hızı sabit tutulmuştur. Kanalda yapılan hız ölçümlerinin $X$ ve $Y$ doğrultusundaki ölçüm noktaları Tablo 1 'de verilmiştir. $Y=0 \mathrm{~cm}$ noktası ile $\mathrm{Y}=60 \mathrm{~cm}$ noktas 1 aras1 bitkili alan, $\mathrm{Y}=60 \mathrm{~cm}$ noktas 1 ile $\mathrm{Y}=120 \mathrm{~cm}$ noktas 1 aras 1 bitkisiz alanı ifade etmektedir. Ölçüm mesafeleri $B=120 \mathrm{~cm}$ kanal genişliği ile boyutsuz hale getirilmiştir. Boyutsuz hale getirilmiş değerler Tablo2'de verilmektedir. Burada, X1, $\mathrm{X} 2, \mathrm{X} 3, \mathrm{X} 4$ ve X5 bitkinin olduğu bölgede yer almaktadır. X5, tam olarak bitkinin bittiği kesittir. Ayrıca, X6, X7, X8, X9, X10, X11, X12 ve X13 ise bitki alanının mansabındaki ölçüm kesitlerini ifade etmektedir. Şekil 5 'te ölçüm noktaları ölçeksiz olarak verilmektedir. Şekil 6'da ise rijit bitki dağılımı görülmektedir. 
Tablo 1. X ve Y doğrultusundaki hız ölçüm noktaları

\begin{tabular}{|c|c|c|c|c|c|c|c|c|c|c|c|c|c|c|}
\hline \multirow{2}{*}{$X$} & Nokta ad1 & $\mathrm{X} 1$ & $\mathrm{X} 2$ & X3 & $\mathrm{X} 4$ & $\mathrm{X5}$ & X6 & X7 & $\mathrm{X} 8$ & X9 & X10 & X11 & X12 & X13 \\
\hline & Mesafe $(\mathrm{cm})$ & 6 & 16 & 26 & 36 & 46 & 56 & 66 & 76 & 86 & 96 & 106 & 116 & 126 \\
\hline \multirow{2}{*}{ Y } & Nokta ad 1 & Y1 & Y2 & Y3 & Y4 & Y5 & Y6 & Y7 & Y8 & Y9 & Y10 & Y11 & - & - \\
\hline & Mesafe $(\mathrm{cm})$ & 20 & 30 & 40 & 50 & 55 & 60 & 65 & 70 & 80 & 90 & 100 & - & - \\
\hline
\end{tabular}

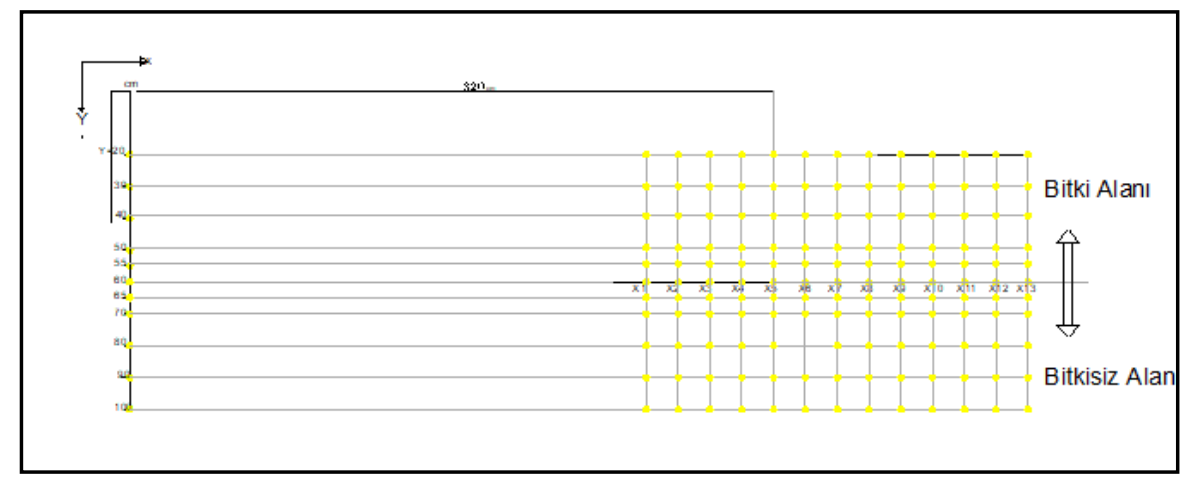

Şekil 5. ADV Hız Ölçüm noktaları

Tablo 2. Yanal ölçüm noktaları ve kanal genişliği ile boyutsuz hale getirilmiş değerler

\begin{tabular}{|l|c|c|c|c|c|c|c|c|c|c|c|}
\hline $\mathrm{Y}(\mathrm{cm})$ & 20 & 30 & 40 & 50 & 55 & 60 & 65 & 70 & 80 & 90 & 100 \\
\hline $\mathrm{Y} / \mathrm{B}$ & 0.17 & 0.25 & 0.33 & 0.42 & 0.46 & 0.50 & 0.54 & 0.58 & 0.67 & 0.75 & 0.83 \\
\hline
\end{tabular}

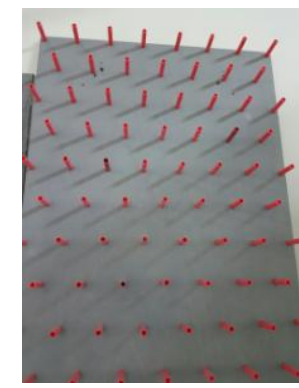

(a)

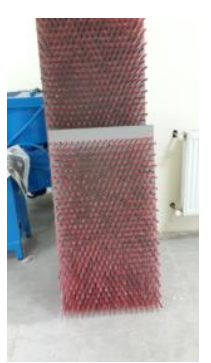

(b)

Şekil 6. Bitki dağılımının görünümü, a) $\mathrm{N}=172 \mathrm{IP} / \mathrm{m}^{2}$, b) $\mathrm{N}=1142 \mathrm{IP} / \mathrm{m}^{2}$

Silindirik cisimler kontrplak üzerine belli bir düzen üzerine yayılmışlardır. Katı cisim hacmi; boşluk ve çapa bağlı olarak 1 nolu denklem ile ifade edilmiştir. Burada (d) bitki çapı, (s) iki bitki arası mesafeyi ifade etmektedir.

$$
\mathrm{V}=[(\sqrt{3} \Pi) / 6] /\left[\left(d^{2}\right) /\left(s^{2}\right)\right]
$$

Tablo 3'de deneyde kullanılan bitki tabakası yoğunlukları ve ah değerleri verilmektedir. $\mathrm{h}_{\mathrm{v}}$ bitki yüksekliğini $\left(\mathrm{h}_{\mathrm{v}}=5 \mathrm{~cm}\right)$ ifade etmektedir. Reynolds Sayısı $\operatorname{Re}=\left(u_{d m} H\right) / v$ $=41000$ ve Froude Sayısı $F r=u_{d m} /(\sqrt{g H})=0.08$ bitkisiz hal için ortalama akım hızı kullanılarak hesaplanmıştır. Burada, $(\mathrm{H})$ akım derinliği, (v) kinematik viskozite ve (g) yerçekimi ivmesidir. Bitkisiz durum için ortalama akım hızı $u_{d m}$ grafik çizimlerinde boyutsuzlaştırma için de kullanılmıştır. Tablo 4'de bu çalışma için geçerli olan hidrolik şartlar özetlenmiştir. 
Tablo 3. Bitki tabakası yoğunlukları ve ah değerleri

\begin{tabular}{|l|c|l|l|l|c|}
\hline $\mathrm{N}\left(\mathrm{IP} / \mathrm{m}^{2}\right)$ & $\begin{array}{c}\mathrm{h}_{\mathrm{v}} \\
(\mathrm{cm})\end{array}$ & \multicolumn{1}{|c|}{$\mathrm{a}=\mathrm{Nd}$} & $\begin{array}{c}\lambda=\mathrm{ah} \\
\text { Boyutsuz bitki } \\
\text { yoğunluğu }\end{array}$ & $\varnothing$ \\
\hline $\mathrm{N} 1=172$ & \multirow{2}{*}{5.0} & $\mathrm{a} 1=172 \times 0.01=1.72 \mathrm{~m}^{-1}$ & $(\mathrm{ah})_{1}=1.72 \times 0.05=0.086$ & $\begin{array}{l}<<0.1 \text { Düsük } \\
\text { yoğunlukta }\end{array}$ & 0.08 \\
\cline { 3 - 6 } $\mathrm{N} 2=1142$ & & $\mathrm{a} 2=1142 \times 0.01=11.42 \mathrm{~m}^{-1}$ & $(\mathrm{ah})_{2}=11.42 \times 0.05=0.571$ & $\begin{array}{l}>0.1 \text { Yüksek } \\
\text { yoğunlukta }\end{array}$ & 0.01 \\
\hline
\end{tabular}

Kanal boyunca akış doğrultusu x ekseni olarak belirlenmiştir. $X=0$ noktası bitki parçasının başlangıç yeri olarak dikkate alınmıştır. Kanal yanal doğrultusu y eksenidir ve $Y=0 \mathrm{~cm}$ noktası bitki parçası üst kenar noktasını ifade etmektedir. $Z$ ile ifade edilen düşey eksen, taban $Z=0$ noktası olarak kabul edilerek konumlandırılmıştır. $\mathrm{Bu}$ üç koordinat ekseni boyunca ADV ölçüm cihazı yardımıyla 120sn ölçüm süresi boyunca $25 \mathrm{~Hz}$ de 3000 ölçüm değeri elde edilmiştir. Koordinat eksenleri doğrultusunda ölçülen hızlar zamansal ortalama $\bar{u}, \bar{v}, \bar{w}$ ve çalkantı bileşeni $u^{\prime}, v^{\prime}, w^{\prime}$ olarak ayrıştırılmıştır. Hız ölçümleri Z doğrultusunda üç derinlikte yapılmıştır.

Tablo 4. Hidrolik şartlar

\begin{tabular}{|c|c|c|c|c|c|c|c|c|c|c|}
\hline & $\begin{array}{c}\mathrm{N} \\
\left(\mathrm{IP} / \mathrm{m}^{2}\right)\end{array}$ & $\phi$ & $\lambda(\mathrm{ah})$ & $\begin{array}{c}\mathrm{L}_{\mathrm{v}} \\
(\mathrm{cm})\end{array}$ & $\begin{array}{c}\mathrm{H} \\
(\mathrm{cm})\end{array}$ & $\begin{array}{c}\mathrm{h}_{\mathrm{v}} \\
(\mathrm{cm})\end{array}$ & $\mathrm{H} / \mathrm{h}_{\mathrm{v}}$ & $\begin{array}{c}\mathrm{u}_{\mathrm{dm}} \\
(\mathrm{cm} / \mathrm{s})\end{array}$ & $\operatorname{Re}$ & $\mathrm{Fr}$ \\
\hline $\begin{array}{c}\text { Durum } 1 \\
\text { h5f1 }\end{array}$ & 172 & 0.01 & 0.086 & \multirow{2}{*}{60} & \multirow{2}{*}{30} & \multirow{2}{*}{5} & \multirow{2}{*}{6} & \multirow{2}{*}{13.6} & \multirow{2}{*}{41000} & \multirow{2}{*}{0.08} \\
\hline $\begin{array}{c}\text { Durum } 2 \\
\text { h5f8 }\end{array}$ & 1142 & 0.08 & 0.571 & & & & & & & \\
\hline
\end{tabular}

Farklı akım derinlikleri ve debilerde ön deneyler gerçekleştirilmiştir. Buna göre, çalışmada dikkate alınacak akım derinliği, $\mathrm{H}=30 \mathrm{~cm}$ ve debi, $\mathrm{Q}=0.033 \mathrm{~m}^{3} / \mathrm{s}$ olarak belirlenmiştir. Düşeyde $Z=0$ taban olarak kabul edilerek $Z 1=0.5 \mathrm{~cm}, Z 2=5 \mathrm{~cm}$ ve $\mathrm{Z} 3=10 \mathrm{~cm}$ olmak üzere 3 farklı derinlikte ölçüm yapılmıştır. Bu derinliklerde yapılan ölçümler ile bitki tabakasında ve bitki tabakası üstündeki hidrodinamik akım yapısının incelenmesi amaçlanmıştır.

\section{Sonuçlar ve tartışma}

Düşeydeki ölçümlerden elde edilen hız değerleri, ortalama hız değerleri ile boyutsuzlaştırılmıştır. Ortalama hız değerleri (2) nolu denklem kullanılarak elde edilmiştir.

$u_{d}(y)=\frac{1}{H(y)} \int_{0}^{H(y)} u_{d z}$

Şekil 7, Şekil 8 ve Şekil 9'da sirasıyla $Z=0,5 \mathrm{~cm}, Z=5 \mathrm{~cm}$ ve $Z=10 \mathrm{~cm}$ mesafelerde bitkisiz kanalda, seyrek ve yoğun bitki hali durumunda kanal en kesiti boyunca alınan hız profilleri verilmektedir. Burada, $h 5 h_{v}=5 \mathrm{~cm}$ 'lik bitki yüksekliğine, f1 düşük yoğunluklu bitki alanına, f8 yüksek yoğunluklu bitki alanına, z11d5 $\mathrm{Z}=0.5 \mathrm{~cm}, \mathrm{z} 16 \mathrm{~d} 5$ $\mathrm{Z}=5 \mathrm{~cm}$ ve $\mathrm{z} 21 \mathrm{~d} 5 \mathrm{Z}=10 \mathrm{~cm}$ derinlikteki ölçümlere karşıllk gelmektedir. X koordinat 
ekseni üzerindeki ölçüm noktaları olan, X6, X16, X26, X36, X46, X56, X66, X76, X86, X96, X106, X116 ve X126 mesafeleri yukarıda Şekil 5'den kontrol edilebilmektedir.
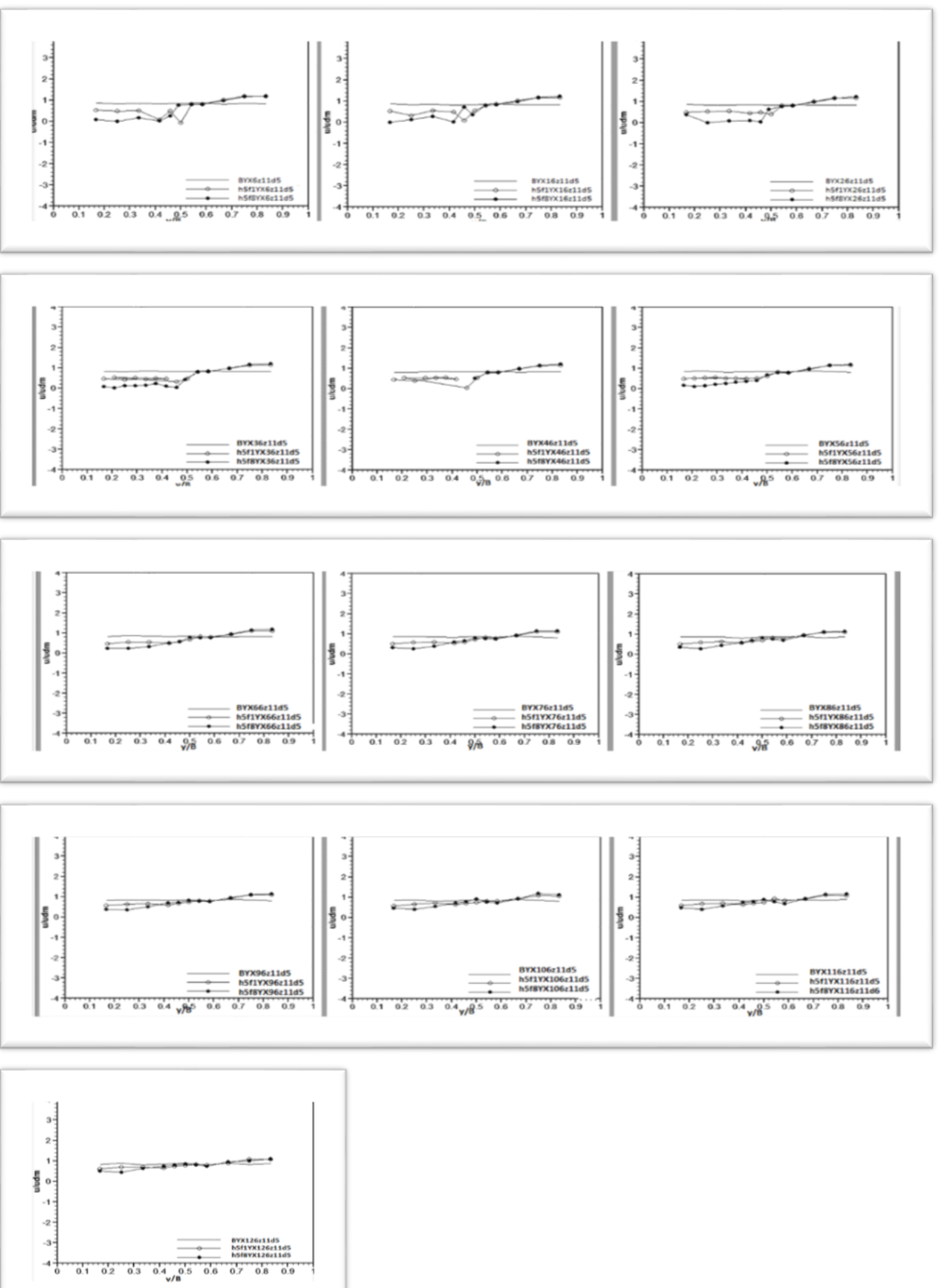

Şekil 7. Z=0.5cm derinlikte yanal eksen boyunca bitkisiz, seyrek bitkili N1=172IP $/ \mathrm{m}^{2}$ ve yoğun bitkili N2=1142IP/ $/ \mathrm{m}^{2}$ durumları için hız profilleri 

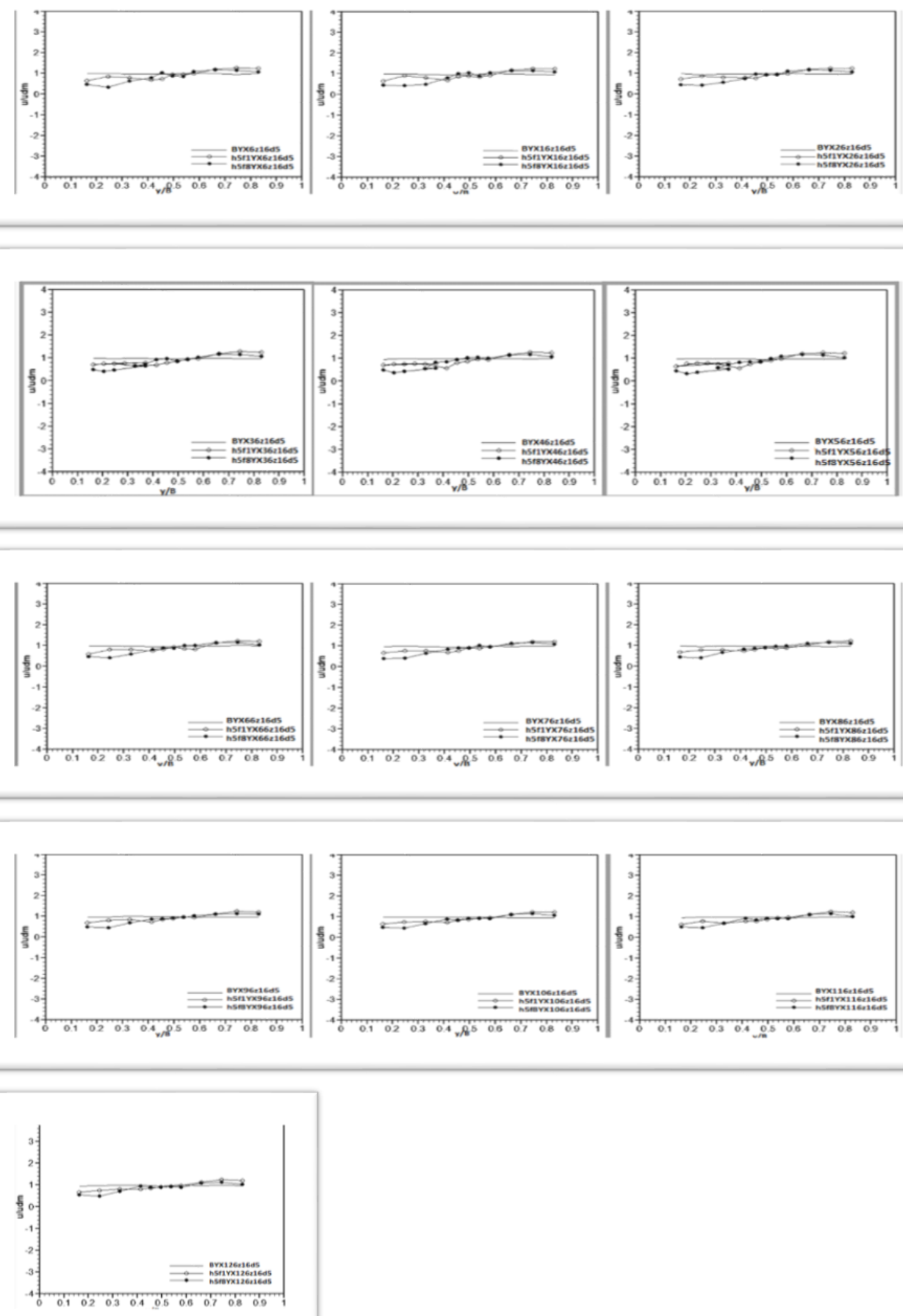

Şekil 8. Z=5cm derinlikte yanal eksen boyunca bitkisiz, seyrek bitkili $\mathrm{N} 1=172 \mathrm{IP} / \mathrm{m}^{2}$ ve yoğun bitkili $\mathrm{N} 2=1142 \mathrm{IP} / \mathrm{m}^{2}$ durumları için hız profilleri 

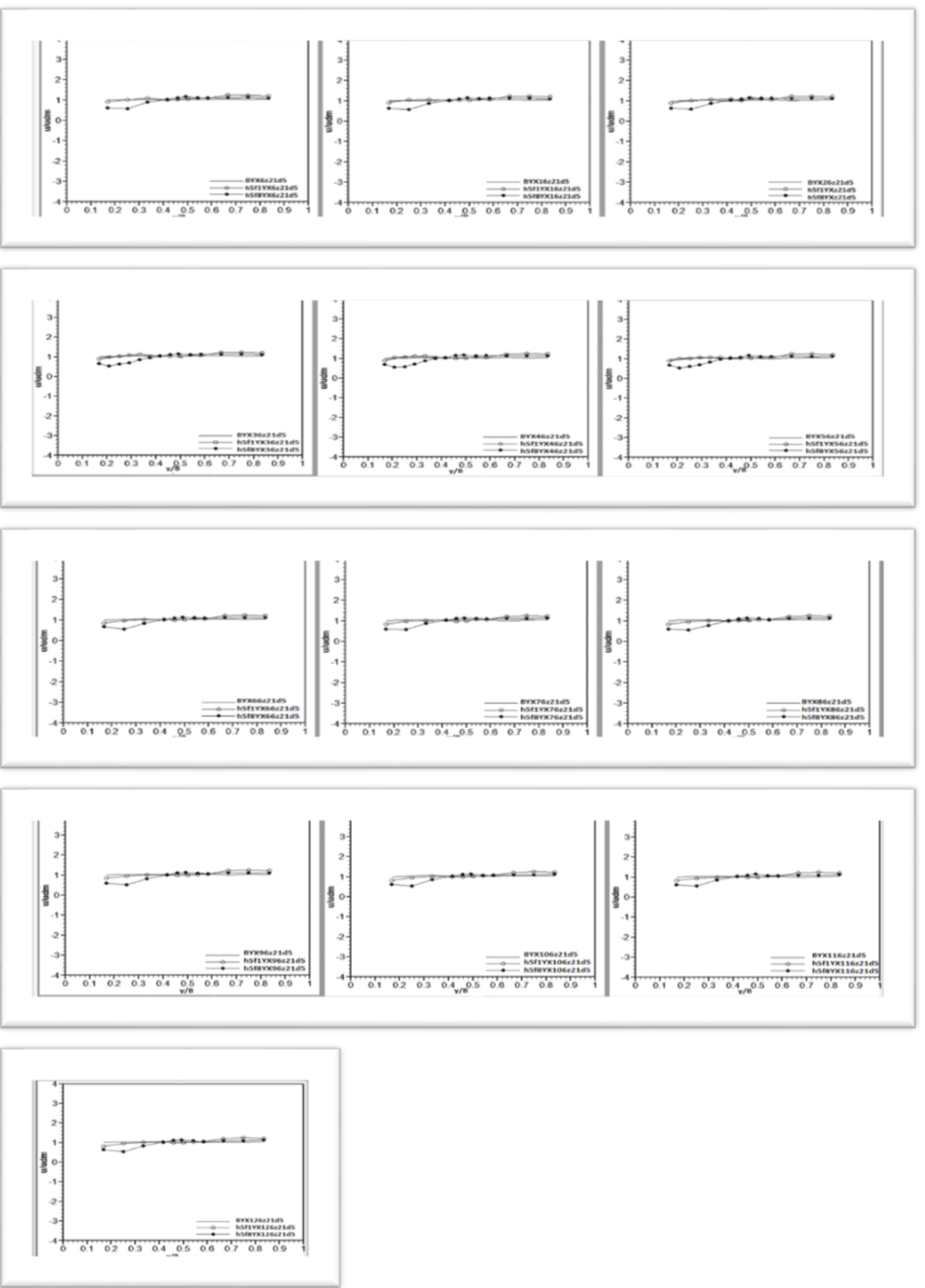

Şekil 9. Z=10cm derinlikte yanal eksen boyunca bitkisiz, seyrek bitkili $\mathrm{N} 1=172 \mathrm{IP} / \mathrm{m}^{2}$ ve yoğun bitkili N2=1142IP $/ \mathrm{m}^{2}$ durumları için hız profilleri

Bu çalışmada, batık bitki örtüsünün açık kanal akımı en kesitinde neden olduğu akım yapısı incelenmiştir. Çalışma sonucunda bitki tabakasının varlığının, akımın hızında bir 
azalmaya neden olduğu görülmüştür. Bitkisiz durum, seyrek bitki tabakalı durum ve yoğun bitki tabakalı durum incelendiğinde, bitki yoğunluğunun artışıyla beraber hızdaki azalmanın daha etkin bir hale geldiği gözlenmiştir. Bu durum Li, Y. (2014) ile uyuşmaktadır [9]. Li, Y. (2014) artan bitki yoğunluğu ile beraber, hız ve debinin, bitki üst kısmı ile su yüzü arasındaki bitkisiz bölümde arttığı ve bitkili kısımda azaldığını gözlemiştir [9]. Bitki üst kısmındaki debinin, bitkili kısımdaki debiye oranının $Q_{u} / Q_{d}$ bitki yoğunluğu artışıyla beraber arttığını söylemektedir [9]. Şekil 7, Şekil 8 ve Şekil 9 incelendiğinde, bitki üst kısmında hızdaki artış görülmektedir. Ayrıca seyrek bitki dağılımı akım üzerinde etkin azalmaya sadece bitki yakınında sebep olmaktayken, daha yoğun bitki parçası akım hızı üzerinde bitki üzerindeki bölgede dahi etkilidir ve bu durum deney sonuçlarından da izlenebilmektedir. $Z=10 \mathrm{~cm}$ derinlik için yapılan deneylerin grafiklerinin yer aldığı Şekil 9'da bu durum daha net olarak görülmektedir. Çalışma sadece tek bir bitki yüksekliği için yapılmıştır. Değişik bitki yükseklikleri ile de deneyin tekrarlanmasının ve sonuçların karşılaştırılmasının bir sonraki çalışmanın konusunu oluşturması planlanmaktadır. Bu tür çalışmaların art-iz bölgesinin daha net anlaşılmasına fayda sağlayacağına inanılmaktadır.

\section{Teșekkür}

$\mathrm{Bu}$ çalışma Adnan Menderes Üniversitesi Bilimsel Araştırma Projeleri (MF-17008) no'lu proje kapsamında desteklenmiştir. Ayrıca yazarlar, deneylerin yapılması esnasında yardımcı olan Kırıkkale Üniversitesi, Mühendislik Fakültesi, İnşaat Mühendisliği öğretim üyesi Doç. Dr. Kubilay CİHAN'a, Adnan Menderes Üniversitesi, İnşaat Mühendisliği Bölümü öğrencileri Canberk KARACASU ve Rıdvan SARIGÜL'e, şekil çizimleri konusunda yardım eden Namık Kemal Üniversitesi, Çorlu Mühendislik Fakültesi, İnşaat Mühendisliği bölümü öğretim üyesi Yrd. Doç. Dr. Ayşe KOPUZ'a teşekkürlerini sunarlar.

\section{Kaynaklar}

[1] Afzalimehr, H., Najfabadi, E.F., and Singh, P.V., Effect of Vegetation on Banks on Distribution of Velocity and Reynolds Stress under Acceleration Flow, Journal of Hydraulic Engineering, 15, 9, 708-713, (2010).

[2] Akgül, M.A., Yilmazer, D., Oguz, E, Kabdasli, M.S., and Yagci, O., The effect of an emergent vegetation (i.e. Phragmistes Australis) on wave attenuation and wave kinematics, Journal of Coastal Research: Special Issue, 65, 1, 147-152, (2013).

[3] Fischer-Antze, T., Stoesser, T., Bates, P., and Olsen, N.R.B. 3D numerical modelling of open-channel flow with submerged vegetation. Journal of Hydraulic Research, 39, 3, 303-310, (2001).

[4] Fonseca, M.S., and W.J. Kenworthy, Effects of current on photosynthesis and distribution of seagrasses, Aquatic Botany, 27, 59-78, (1987).

[5] Haung, B., Lai, G and Qiu, J., Experimental research on influence of vegetated floodplains upon flood carrying capacity of river, Journal of Hydrodynamics, Ser. A, 14, 4, 468-474, (1999). 
[6] Huai, W.X., Zeng, Y.H., Xu, Z.G. and Yang, Z.H. Three-layer model for vertical velocity distribution in open channel flow with submerged rigid vegetation. Advances in Water Resources, 32, 487-492, (2009).

[7] Järvelä, J., Influence of vegetation on flow structure in floodplains and wetlands, In Sánchez-Arcilla A, Bateman A, editors, 3rd IAHR Symposium on River, Coastal and Estuarine Morphodynamics, Barcelona, 1-5 September 2003. Madrid: IAHR, 845-856, (2003).

[8] Järvelä, J., Effect of submerged flexible vegetation on flow structure and resistance. Journal of Hydrology, 307, 233-241, (2005).

[9] Li, Y., Wang, Y., Anim, D.O., Tang, C., Du, W., Ni, L., Yu, Z., and Acharya, K. Flow characteristics in different densities of submerged flexible vegetation from an open-channel flume study of artificial plants. Geomorphology, 204, 314324, (2014).

[10] Nepf, H.M., Drag, turbulence, and diffusion in flow through emergent vegetation, Water Resources, 35, 2, 479-489, (1999).

[11] Nepf, H.M. and Vivoni, E.R., Flow Structure in depth limited, vegetated flow, Journal of Geophysical Research, 105, C12, 28547-28557, (2000).

[12] Nepf, H. M., Flow and treansport in regions with aquatic vegetation, Annual Review Fluid Mechanics, 44, 123-42, (2012).

[13] Nezu, I. and Okamoto, T., Large eddy simulation of 3-D flow structure and mass transport in open channel flows with submerged vegetations, Journal of hydroEnvironment Research, 4, 185-197, (2010).

[14] Ni, H. and Gu, F., Roughness coefficient of non-submerged reed, Journal of Hydrodynamics, Ser. A, 20, 2, 167-173, (2005).

[15] Okamoto T., and Nezu, I., Spatial evolution of coherent motions in finite-length vegetation patch flow, Environmental Fluid Mechanics, 13, 417-434, (2013).

[16] Raupach M.R., Canopy Transport Processes, In: Steffen W.L., Denmead O.T. (eds) Flow and Transport in the Natural Environment: Advances and Applications, Springer, Berlin, Heidelberg, 95-127(1988),

[17] Sarker, A., Flow measurement around scoured bridge piers using AcousticDoppler Velocimeter-ADV, Flow measurement and instrumentations, 9, 217227, (1998).

[18] Stephen, U. and Gutknecht, D., Hydraulic resistance of submerged flexible vegetation, Journal of Hydrology, 269, 27-43, (2002).

[19] WinADV32(v.2.027) Manual 2009

[20] Wilson, C.A.M.E. Flow resistance models for flexible submerged vegetation. Journal of Hydrology, 342, 3-4, 213-222, (2007).

[21] Yüksel Ozan, A., Bitki parçasının açık kanal en kesiti boyunca neden olduğu akım yapısı, Pamukkale Üniversitesi Mühendislik Bilimleri Dergisi, PAJES71300, DOI: 10.5505/pajes.2016.71300, (2016).

[22] Zhu, L. and Chen, Q., Numerical modelling of surface waves over submerged flexible vegetation, American Society of Civil Engineers, Journal of Engineering Mechanics, 142, 8, A40115001-1/A4015001-12, (2015). 